the Hospital which perpetuates his name. Charles Darwin studied patients at the Hospital and sought advice from Crichton-Browne for his work Expression of Emotion in Man and the Animals.

Those taught to think that the history of the mental hospitals is a 'bad thing' will be reoriented by this illuminating account of clinical, scientific, managerial and humane endeavour. The reading of the book may prompt a visit to the museum at Stanley Royd Hospital: open Wednesdays 10 a.m.-1 p.m. and 1.30-4 p.m. Mr Ashworth may be contacted by phone: 0924201688.

St James's University Hospital Leeds LS9 $7 T F$

\section{Section 5(4) of Mental Health Act, 1983}

\section{Dear Sirs}

Drs Bowler and Cooper's paper about the use of Section 5(4) of the 1983 Mental Health Act (Psychiatric Bulletin, March, 1993, 17, 147-149) is an important contribution to the limited literature on this subject. An inner-related, and arguably just as important, issue is the number of patients who are detained by nurses without using the provisions of the Act.

In our study (Allen \& Johnstone, 1992), we found that out of 98 nurses who were eligible to detain patients, 22 admitted to having detained them by use of restraint without using Section 5(4). Interestingly, an earlier survey of the same cohort by us revealed just 12 nurses who were willing to admit this; we postulated that this was due to the feedback given in our second survey which enabled nurses to be more open about this rather difficult question.

A potentially worrying finding was the apparent lack of correlation between the decision to prevent patients leaving and their potential 'detainability'; out of 22 patients detained by restraint without using Section 5(4) only 12 were deemed by nurses to have a 'serious mental illness' so, by their own definition, would not have been detainable under the Act.

Restraint was only for a few minutes in 20 cases but for up to an hour in two cases, and over an hour in another; the latter three being 'seriously mentally ill'. We concluded that there may well be grounds for restraining people under common law for their own protection but that this did not normally include detaining them in hospital against their will and we questioned whether nurses were making reasoned judgements when deciding whether to exercise the provisions of the Act.

It was particularly interesting that during the period of our survey, which lasted for six months, Section 5(4) was used on ten occasions, compared with its previous use: ten times in the four and a half years since the implementation of the Act. We suggested that raising staff awareness and confirming the acceptability of the Section influenced their behaviour.

\section{Fromeside Clinic}

Danny Allen

Bristol BSI6 IED

\section{Reference}

AlLen \& Johnstone (1992) The use of section 5(4) of the Mental Health Act, 1983. British Joumal of Clinical \& Social Psychiatry, 8, 72-76.

\section{Questioning clinical judgement}

\section{DEAR SIRS}

If Dr Akinkunmi (Psychiatric Bulletin, March 1993 $17,175)$ continues in old age psychiatry, he will soon become accustomed to having his clinical judgement queried by all sorts of people, not just Members of Parliament - although I admit it is not usual for MPs to get over-involved in person, choosing usually to write to Chairmen of Health Authorities or to the Health Services Commissioner.

One of the worst examples in my experience (some years ago now) was with a County Councillor who, hearing that an elderly depressed man was to be allowed home, went to the ward and bullied the nursing staff into letting her make a full "examination" of the patient, which included testing his ability to walk and climb stairs; in due course I was telephoned and given her opinion that my patient was not ready for discharge. This was conveyed to the family who resisted discharge so effectively that it could not take place; the patient just "gave up" and died a few months later.

"Dolbeau", 1, Wall Park Road

D. M. D. WHITE

Brixham, Devon, TQ5 9UE

\section{Training in liaison psychiatry}

\section{Dear Sirs}

I am delighted to see liaison psychiatry having a higher profile but have to say that the recommendations from the Liaison Psychiatry Group Executive Committee do not go far enough. What is missing is an explicit recognition of the essential quality of liaison psychiatry, which is the relationship between the psychiatrist and the hospital department where he or she works. Trainees who are simply supervised on clinical work will fail to understand what is happening to them, and to their colleagues if this is not addressed in supervision. As we all know, regular doctors mistrust psychiatrists, and a major part of the liaison task is joining the department or ward being served. This is comparable to an anthropological exercise, and requires some discussion between 